Goldschmidt 2021 Abstract

https://doi.org/10.7185/gold2021.7818

\section{0 years of Quarantine Extraterrestrial Sample Analyses methodology}

ALEXANDRE S SIMIONOVICI ${ }^{1}$, LAURENCE LEMELLE ${ }^{2}$, PIERRE BECK ${ }^{3}$, FRANCOIS FIHMAN ${ }^{4}$, TOM

SCHOONJANS $^{5}$, REMI TUCOULOU TACHOUERES ${ }^{6}$, LARA MALDANIS $^{7}$, KATERYNA KIRYUKHINA ${ }^{8}$ AND MICHEL $\mathrm{VISO}^{8}$

${ }^{1}$ University Grenoble Alpes

${ }^{2}$ LGL-TPE, ENS de Lyon, Université de Lyon, CNRS

${ }^{3}$ IPAG, Univ. Grenoble Alpes

${ }^{4} 6 \mathrm{TEC}$

${ }^{5}$ Rosalind Franklin Institute

${ }^{6}$ European Synchrotron Radiation Facility

${ }^{7}$ Université Grenoble Alpes

${ }^{8} \mathrm{CNES}$

Presenting Author: alexandre.simionovici@univ-grenoblealpes.fr

NASA's MARS2020 space mission will sample soil containing putative traces of life and return them to Earth after 2031. Only Sample Return to Earth will guarantee access to the detailed, unique analyses we have been developing since 2001, when Mars Sample Return (MSR) was launched as a NASA CNES project. Throughout the last 20 years, with CNES, we developed, tested and patented [1] a triple container, for our QESA (Quarantine Extraterrestrial Sample Analysis) nondestructive/multiprobe analysis methodology, imposed by COSPAR Planetary Protection requirements. Our BSL4 minicuration/transport/containment unit, comprises 3 nested containers, leakproof-monitored, protecting both Earth and potential germs, from coming into contact [2]. XRF/XAS/XRD analyses of meteoritic samples helped estimate Minimal Detection Limits of low/high Z $(\mathrm{P} / \mathrm{S} / \mathrm{K} / \mathrm{Ca} / \mathrm{Ti} / \mathrm{Cr} / \mathrm{Mn} / \mathrm{Fe} / \mathrm{Ni} / \mathrm{Cu} / \mathrm{Zn})$ on host minerals. For $\mathrm{XCT}$, precession and rotation precision were tested for the internal mini-rotation drive and the absorption/scattering effects of triple container walls on the quality of $3 \mathrm{D}$ reconstruction. Results on meteoritic or Archean rocks [3-7] have proven feasibility of $2 \mathrm{D} / 3 \mathrm{D}$ imaging of microorganisms on mineral hosts or aqueous alteration phases, potentially indicative of life on Martian meteorites; however, special requirements are mandatory when measuring in fluorescence submicron mineral grains containing organics [8].

Hyperspectral XRF/XRD mineral phase maps, 2D slice XRF fluo-tomography through grains, XAS oxidation state chemical mapping gradients, XCT full-field phase contrast tomography as well as lab-based Raman/IR tests were performed and estimated slightly worse realistic detection limits through the 3 wall containers. QESA is now ready for MSR.

- $\quad$ A.Simionovici and CNES, European Patent Office \# EP2411791A1, 2010.

- A.Simionovici, L.Lemelle, et al., Proc. $2^{\text {nd }}$ Int. Conf. on MSR Missions, Berlin, 2018
- $\quad$ L.Lemelle, A.Simionovici et al., Am. Min. 89 (4), 547-553, 2004.

- $\quad$ E.Zolensky, L. Lemelle, A.Simionovici et al., Science 314, 1735-1739, 2006

- G.J.Flynn, L.Lemelle, A.Simionovici et al., Science 314, 1731-1735, 2006

- A.J.Westphal, L.Lemelle, A.Simionovici et al., Science 345, 786-791, 2014

- A.Simionovici, L.Lemelle, et al., Meteor. \& Planet. Sci. 49, 1612-1625, 2014

- L.Lemelle, A.Simionovici, et al., Trends Anal. Chem. 91, 104-111, 2017 